Original Article

\title{
Comparative effects of lidocaine and esmolol in attenuating the hemodynamic response to laryngoscopy and intubation
}

\author{
Koju RB ${ }^{1}$, Dongol $Y^{2}$ \\ ${ }^{1}$ Department of Anesthesia and Critical Care, KIST Medical College and Teaching Hospital, Lalitpur, Nepal \\ ${ }^{2}$ Department of Biochemistry, KIST Medical College and Teaching Hospital, Lalitpur, Nepal \\ Correspondence: Dr. Ram Bhakta Koju, Department of Anesthesia and Critical Care
}

KIST Medical College and Teaching Hospital, Lalitpur, Nepal

E-mail: dr.koju@gmail.com

\begin{abstract}
Introduction: Transient hemodynamic instability is an inevitable outcome of laryngoscopy and intubation which can have serious effects in patients with COPD, heart disease and hypertension. Hemodynamic stability is one of the main goals of the anesthesiologist. This study was performed to compare the safety and effectiveness of lidocaine and esmolol in comparison to placebo-control group, in modifying the hemodynamic response to laryngoscopy and intubation.

Methods: After approval of the study protocol by the institutional review board (IRB), written informed consent was obtained from each patient. It was a randomized placebo-controlled, doubleblinded study. 75 patients of American Society of Anesthesiologists physical status I and II, scheduled for general surgery under GA, aged between 20-60 years were randomly allocated into three groups: placebo control group $(n=25)$, lidocaine group $(n=25)$ and esmolol group $(n=25)$. Placebo group received $12 \mathrm{ml}$ normal saline, lidocaine group received $1.5 \mathrm{mg} / \mathrm{kg}$ lidocaine (total volume $12 \mathrm{ml}$ ) and esmolol group received $1.4 \mathrm{mg} / \mathrm{kg}$ esmolol (total volume $12 \mathrm{ml}$ ).

Results: Following laryngoscopy and intubation, the increase in systolic blood pressure, diastolic blood pressure and heart rate were significantly lower $(\mathrm{p}<0.05)$ in esmolol group compared to the lidocaine and placebo group but there was no statistical significance $(\mathrm{p}>0.05)$ between control and lidocaine group.

Conclusion: Esmolol $1.4 \mathrm{mg} / \mathrm{kg}$ IV was significantly more effective in controlling the hemodynamic response following laryngoscopy and intubation in comparison to lidocaine $1.5 \mathrm{mg} / \mathrm{kg}$.
\end{abstract}

Key Words: Cardiovascular response; Esmolol; Hemodynamics; Intubation; Laryngoscopy; Lidocaine.

\section{Introduction}

Hemodynamic stability is one of the main goals of any anesthesiologist. The main cause of transient hemodynamic instability and interruption of patients' airway reflexes is laryngoscopy and intubation. ${ }^{1}$ It has detrimental effects on the other organs especially in patients with COPD, heart diseases and high blood pressure and associated with morbidity at times., ${ }^{2,3}$ They are associated with hemodynamic changes due to sympathetic response leading to increase in plasma concentration of adrenaline and nor-adrenaline.

Hemodynamic response to laryngoscopy and intubation was first described by Reid and Brace in $1940 .{ }^{4}$ There are several methods in modifying the hemodynamic response, 
e.g. deep anesthesia and use of ganglion blockers. ${ }^{5}$ Similarly, several cardiovascular drugs such as lidocaine, esmolol, nitroprusside, gabapentin, pregabalin, dexmedetomidine, verapamil and clonidine have been tested to blunt the acute hemodynamic response to tracheal intubation. ${ }^{6-11}$

Sodium nitroprusside and nitroglycerine are effective to blunt the acute hemodynamic response to tracheal intubation but the safety and efficacy of IV bolus administration requires further evaluation. ${ }^{8,9}$ Sodium nitroprusside and nitroglycerine can promote severe hypotension and tachycardia. ${ }^{12}$ The use of verapamil and clonidine have failed to gain clinical acceptance due to variable onset and relatively long duration of action. ${ }^{13}$ Lidocaine administration prior to induction of anesthesia is effective in controlling the hypertension and tachycardia in response to laryngoscopy and tracheal intubation, but some studies have proved that lidocaine is not effective in blunting the hemodynamic response to laryngoscopy and intubation. ${ }^{14-17}$

Various studies have also shown that esmolol is more effective in attenuating the sympathetic response to laryngoscopy and intubation. ${ }^{18}$ Beta-adrenergic receptor blocking drugs, e.g. esmolol, is found to be more effective in controlling the increase in heart rate than the rise in blood pressure. ${ }^{19} \mathrm{We}$, therefore, designed this study to compare the safety and effectiveness of the standard IV bolus doses of lidocaine and esmolol to blunt the hemodynamic response to laryngoscopy and tracheal intubation.

\section{Methods}

This randomized, double-blinded, placebo-controlled study was conducted at KIST Medical College \& Teaching Hospital, Lalitpur, from July $1^{\text {st }}$ to December 31 $1^{\text {st }}, 2014$. The study design was approved from the institutional review board (IRB) and written informed consent was received from each patient after detailed explanation of the procedure. A power analysis showed that 24 patients in each group (placebo, esmolol and lidocaine) would be sufficient to detect a 5 units' difference in mean arterial pressure after 3 minutes of intubation with a power of $80 \%$ and $95 \%$ confidence interval. ${ }^{2}$ Power analysis done based on previous literature of similar studies, seventy-five patients were selected. ${ }^{2}$ These seventy-five patients of American Society of Anesthesiologists (ASA) physical status I and II, aged between 20 to 60 years and weighed $55-77 \mathrm{~kg}$, who are undergoing elective surgery under general anesthesia were randomly allocated using manual lottery (closed envelope) method to one of the three groups: placebo group $(n=25)$, lidocaine group $(n=25)$ and esmolol group $(n=25)$. Patients with a history of cardiovascular diseases, cerebrovascular diseases, psychosis, recent drug abuse, respiratory problem, difficulty in intubation or repeated attempting of intubation and pregnancy were excluded from the study.

Pre-anesthetic check-up was done in all the patients one day before surgery and all the patients were treated with diazepam $5 \mathrm{mg}$ orally at night before surgery.

After arrival at the operation theater, baseline parameters like heart rate (HR), systolic blood pressure (SBP) and the diastolic blood pressure (DBP) were measured by NIBP. In addition, $\mathrm{SpO}_{2}$ and $\mathrm{ECG}$ were monitored continuously.

IV cannulation was done with 18 gauge cannula. Patients received one of the three standardized treatment regimens prior to laryngoscopy. Placebo group received $12 \mathrm{ml}$ normal saline, lidocaine group received $1.5 \mathrm{mg} / \mathrm{kg}$ IV lidocaine (total volume $12 \mathrm{ml}$ ) and esmolol group received $1.4 \mathrm{mg} / \mathrm{kg}$ esmolol (total volume $12 \mathrm{ml}$ ) based on institutional protocol. All the drugs were prepared to the total volume of $12 \mathrm{ml}$ to prevent biasness. Drug preparation and randomization of the patients were done by the anesthetic assistant who was not involved in the study. The patients and the researcher were blinded with the stress blunting agents given.

Induction was done with pethidine $1 \mathrm{mg} / \mathrm{kg}$, propofol $2 \mathrm{mg} /$ $\mathrm{kg}$ and vecuronium $0.15 \mathrm{mg} / \mathrm{kg}$ IV (at time $0 \mathrm{~min}$ ). After 3 minutes of injection of vecuronium bromide, endotracheal intubation was done. Anesthesia was maintained with $1 \%$ to $1.5 \%$ isoflurane with oxygen and vecuronium. All intubation were done within 30 seconds. Then SBP, DBP and HR were recorded just after intubation, 1 minute, 2 minutes, 5 minutes and 10 minutes of intubation. Hemodynamic response to laryngoscopy and the intubation was completed within 30 minutes after endotracheal intubation.

Data was analyzed using SPSS 20.0. Statistical tests applied were student t-test, analysis of vatiancem Chi-square test, mean with standard deviation wherever applicable and p-value $<0.05$ was considered statistically significant.

\section{Results}

Demographic characteristics of the three groups (placebo, lidocaine and esmolol) were compared as shown in Table 1. Enrolled patients were between $20-60$ years of age and $55-77 \mathrm{~kg}$ body weight. The difference among the groups was statistically not significant. 
Table 1: Demography and ASA status of the patients in placebo, lidocaine and esmolol group

$\begin{array}{lllll}\text { Variables } & & \text { Placebo }(\mathbf{n = 2 5}) & \text { Lidocaine }(\mathbf{n}=\mathbf{2 5}) & \text { Esmolol }(\mathbf{n = 2 5}) \\ \text { Age }(\text { Yrs }) & & 42.64 \pm 12.68 & 40.32 \pm 11.83 & 37.24 \pm 11.83 \\ \text { Weight }(\mathbf{K g s}) & & 64.12 \pm 4.12 & 65.56 \pm 3.65 & 66.56 \pm 5.08 \\ \text { Sex } & \text { M } & 7 & 5 & 6 \\ & \text { F } & 16 & 20 & 19 \\ \text { ASA physical status } & \text { I } & 23 & 22 & 21 \\ & \text { II } & 2 & 3 & 4\end{array}$

The differences in the mean SBP just after intubation, at 1 minute, 2 minutes, 5 minutes and 10 minutes between the placebo and esmolol group (Table 2) were statistically significant ( $\mathrm{p}$-value $=0.00,0.02,0.00,0.04$ and 0.03 respectively). However, the differences in the mean SBP between the placebo and lidocaine group (Table 3) were not statistically significant ( $\mathrm{p}$-value $=0.28,0.21,0.21,0.15$ and 0.15 respectively). When comparing the differences in the mean SBP between the esmolol group and the lidocaine group, statistically significant difference is observed only just after intubation (Table 4). Although statistically insignificant, the mean SBP at 1 minute, 2 minutes, 5 minutes and 10 minutes were lower in esmolol group than in lidocaine group.

Table 2: Mean systolic blood pressure $(\mathrm{mmHg})$ between placebo and esmolol groups

$\begin{array}{llll}\text { Time } & \text { Placebo }(\mathbf{n}=\mathbf{2 5}) & \text { Esmolol }(\mathbf{n}=\mathbf{2 5}) & \mathbf{p} \text {-value } \\ \text { Before intubation } & 123.76 \pm 14.07 & 128.08 \pm 15.55 & 0.2 \\ \text { Just after intubation } & 151.6 \pm 12.13 & 126 \pm 13.99 & 0 \\ 1 \mathrm{~min} & 137 \pm 15.35 & 115.56 \pm 15.60 & 0.025 \\ 2 \mathrm{~min} & 125.92 \pm 14.67 & 106.16 \pm 15.36 & 0.008 \\ 5 \mathrm{~min} & 121.08 \pm 14.24 & 98.36 \pm 10.14 & 0.043 \\ 10 \mathrm{~min} & 118.28 \pm 13.13 & 103.6 \pm 17.33 & 0.035\end{array}$

Table 3: Mean systolic blood pressure $(\mathrm{mmHg})$ between placebo and lidocaine groups

$\begin{array}{llll}\text { Time } & \text { Placebo }(\mathrm{n}=25) & \text { Lidocaine }(\mathrm{n}=25) & \mathrm{p} \text {-value } \\ \text { Before intubation } & 123.76 \pm 14.0 & 131.84 \pm 14.4 & 0.154 \\ \text { Just after intubation } & 151.6 \pm 12.1 & 155.52 \pm 16.3 & 0.281 \\ 1 \mathrm{~min} & 137 \pm 15.3 & 135.40 \pm 18.8 & 0.211 \\ 2 \mathrm{~min} & 125.92 \pm 14.6 & 124.36 \pm 15.0 & 0.211 \\ 5 \mathrm{~min} & 121.08 \pm 14.2 & 118.40 \pm 17.0 & 0.159 \\ 10 \mathrm{~min} & 118.28 \pm 13.1 & 118.20 \pm 17.1 & 0.152\end{array}$


Table 4: Mean systolic blood pressure ( $\mathrm{mm} \mathrm{Hg}$ ) between esmolol and lidocaine group

$\begin{array}{llll}\text { Time } & \text { Esmolol }(\mathbf{n}=\mathbf{2 5}) & \text { Lidocaine }(\mathbf{n}=\mathbf{2 5}) & \text { p-value } \\ \text { Before intubation } & 128.08 \pm 15.5 & 131.84 \pm 14.4 & 0.438 \\ \text { Just after intubation } & 126.00 \pm 13.9 & 155.52 \pm 16.3 & 0.005 \\ 1 \mathrm{~min} & 115.56 \pm 15.6 & 135.40 \pm 18.8 & 0.158 \\ 2 \mathrm{~min} & 106.16 \pm 15.3 & 124.36 \pm 15.0 & 0.111 \\ 5 \mathrm{~min} & 98.36 \pm 10.1 & 118.40 \pm 17.0 & 0.162 \\ 10 \mathrm{~min} & 103.60 \pm 17.3 & 118.20 \pm 17.1 & 0.261\end{array}$

Similarly, the mean DBP just after intubation, at 1 minute, 2 minutes and 5 minutes between the placebo and esmolol groups (Table 5) were statistically significant with p-value $=0.00,0.009,0.015$, and 0.015 respectively but at 10 minutes it was not statistically significant with p-value $=0.089$. On the other hand, the mean DBP just after intubation, at 1 minute, 2 minutes, 5 minutes and 10 minutes between the placebo and lidocaine groups were not statistically significant with $\mathrm{p}$-value $=0.141,0.061,0.312,0.106$ and 0.275 respectively (Table 6). Likewise, the mean DBP between the esmolol group and the lidocaine group (Table7) was statistically significant just after intubation but insignificant at 1 minute, 2 minutes, 5 minutes and 10 minutes. The mean DBP values were lower in the esmolol group than in the lidocaine group.

Table 5: Mean diastolic blood pressure (mmHg) between placebo and esmolol groups

$\begin{array}{llll}\text { Time } & \text { Placebo }(\mathrm{n}=25) & \text { Esmolol }(\mathrm{n}=25) & \mathrm{p} \text {-value } \\ \text { Before intubation } & 76.6 \pm 6.7 & 80.08 \pm 9.4 & 0.582 \\ \text { Just after intubation } & 100.60 \pm 10.4 & 80.84 \pm 10.8 & 0 \\ 1 \mathrm{~min} & 91.24 \pm 11.7 & 76.00 \pm 12.0 & 0.009 \\ 2 \mathrm{~min} & 84.76 \pm 13.1 & 67.36 \pm 10.7 & 0.015 \\ 5 \mathrm{~min} & 78.72 \pm 10.7 & 61.92 \pm 7.1 & 0.015 \\ 10 \mathrm{~min} & 76.04 \pm 7.7 & 67.08 \pm 12.6 & 0.089\end{array}$

Table 6: Mean diastolic blood pressure $(\mathrm{mmHg})$ between placebo and lidocaine groups

$\begin{array}{llll}\text { Time } & \text { Placebo }(\mathrm{n}=25) & \text { Lidocaine }(\mathrm{n}=25) & \mathrm{p} \text {-value } \\ \text { Before intubation } & 76.6 \pm 6.7 & 80.16 \pm 9.6 & 0.469 \\ \text { Just after intubation } & 100.60 \pm 10.4 & 97.12 \pm 11.6 & 0.141 \\ 1 \mathrm{~min} & 91.24 \pm 11.7 & 88.32 \pm 13.5 & 0.061 \\ 2 \mathrm{~min} & 84.76 \pm 13.1 & 80.00 \pm 12.1 & 0.312 \\ 5 \mathrm{~min} & 78.72 \pm 10.7 & 77.2 \pm 13.5 & 0.106 \\ 10 \mathrm{~min} & 76.04 \pm 7.7 & 76.56 \pm 12.5 & 0.275\end{array}$


Table 7: Mean diastolic blood pressure (mmHg) between esmolol and lidocaine groups

$\begin{array}{llll}\text { Time } & \text { Esmolol }(\mathrm{n}=25) & \text { Lidocaine }(\mathrm{n}=25) & \mathrm{p} \text {-value } \\ \text { Before intubation } & 80.08 \pm 9.4 & 80.16 \pm 9.6 & 0.503 \\ \text { Just after intubation } & 80.84 \pm 10.8 & 97.12 \pm 11.6 & 0.001 \\ 1 \mathrm{~min} & 76.00 \pm 12.0 & 88.32 \pm 13.5 & 0.084 \\ 2 \mathrm{~min} & 67.36 \pm 10.7 & 80.00 \pm 12.1 & 0.122 \\ 5 \mathrm{~min} & 61.92 \pm 7.1 & 77.2 \pm 13.5 & 0.08 \\ 10 \mathrm{~min} & 67.08 \pm 12.6 & 76.56 \pm 12.5 & 0.375\end{array}$

The differences in the mean HR just after intubation, at 1 minute, 2 minutes, 5 minutes and 10 minutes between the placebo group and the esmolol group (Table 8) were statistically significant (p-value $=0.00,0.01,0.01,0.03$ and 0.01 respectively) whereas the differences between the placebo group and lidocaine group (Table 9) were not statistically significant with p-values $0.07,0.08,0.27,0.17$ and 0.23 respectively. Likewise, the mean HR between the esmolol group and the lidocaine group (Table 10) was statistically significant just after intubation but insignificant at 1 minute, 2 minutes, 5 minutes and 10 minutes. The mean HR values were lower in the esmolol group than in the lidocaine group.

Table 8: Mean heart rate between placebo and esmolol group

$\begin{array}{llll}\text { Time } & \text { Placebo }(\mathrm{n}=25) & \text { Esmolol }(\mathrm{n}=25) & \mathrm{p} \text {-value } \\ \text { Before intubation } & 76.00 \pm 12.1 & 81.00 \pm 18.4 & 0.21 \\ \text { Just after intubation } & 98.60 \pm 13.8 & 79.64 \pm 13.6 & 0.001 \\ 1 \mathrm{~min} & 84.84 \pm 13.9 & 75.16 \pm 13.7 & 0.082 \\ 2 \mathrm{~min} & 79.92 \pm 8.9 & 70.24 \pm 12.8 & 0.019 \\ 5 \mathrm{~min} & 77.04 \pm 10.4 & 65.56 \pm 10.9 & 0.037 \\ 10 \mathrm{~min} & 73.04 \pm 8.8 & 65.08 \pm 15.8 & 0.011\end{array}$

Table 9: Mean heart rate between placebo and lidocaine group

$\begin{array}{llll}\text { Time } & \text { Placebo }(\mathrm{n}=25) & \text { Lidocaine }(\mathrm{n}=25) & \mathrm{p} \text {-value } \\ \text { Before intubation } & 76.00 \pm 12.1 & 79.76 \pm 16.1 & 0.465 \\ \text { Just after intubation } & 98.60 \pm 13.8 & 95.00 \pm 17.7 & 0.071 \\ 1 \mathrm{~min} & 84.84 \pm 13.9 & 83.20 \pm 18.4 & 0.082 \\ 2 \mathrm{~min} & 79.92 \pm 8.9 & 78.12 \pm 17.5 & 0.276 \\ 5 \mathrm{~min} & 77.04 \pm 10.4 & 73.36 \pm 15.3 & 0.17 \\ 10 \mathrm{~min} & 73.04 \pm 8.8 & 70.36 \pm 9.6 & 0.23\end{array}$

Table 10: Mean heart rate between esmolol and lidocaine group

$\begin{array}{llll}\text { Time } & \text { Esmolol }(\mathrm{n}=25) & \text { Lidocaine }(\mathrm{n}=25) & \mathrm{p} \text {-value } \\ \text { Before intubation } & 81.00 \pm 18.4 & 79.76 \pm 16.1 & 0.302 \\ \text { Just after intubation } & 79.64 \pm 13.6 & 95.00 \pm 17.7 & 0.004 \\ 1 \mathrm{~min} & 75.16 \pm 13.7 & 83.20 \pm 18.4 & 0.266 \\ 2 \mathrm{~min} & 70.24 \pm 12.8 & 78.12 \pm 17.5 & 0.311 \\ 5 \mathrm{~min} & 65.56 \pm 10.9 & 73.36 \pm 15.3 & 0.189 \\ 10 \mathrm{~min} & 65.08 \pm 15.8 & 70.36 \pm 9.6 & 0.064\end{array}$


There was no significant difference between baseline mean SBP with p-value 0.200 (between placebo and esmolol group; Table 2), p-value 0.154 (between placebo and lidocaine group; Table 5) and p-value 0.438 (between esmolol and lidocaine group; Table 7). There was statistically significant blunting of laryngoscopic and intubating stress response as indicated by the p-value just after intubation, at 1 minute, 2 minutes, 5 minutes and 10 minutes in esmolol group (Table 2) than in lidocaine group when compared to placebo group in terms of mean SBP, mean DBP and mean HR. Though few patients developed bradycardia, none of them required any intervention. Dramatic superiority of esmolol over lidocaine was observed (Figure 1, Figure 2 and Figure 3)

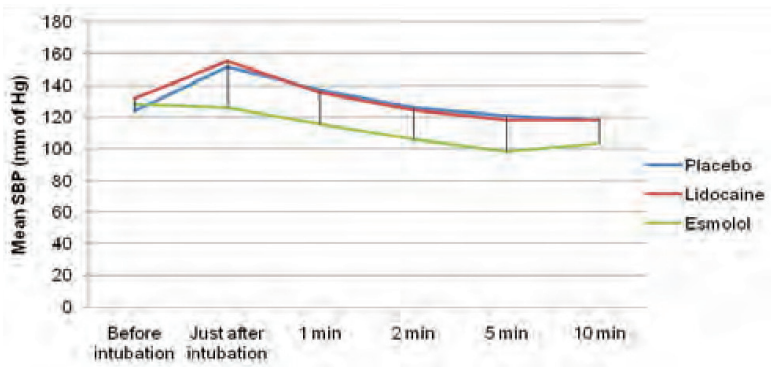

Figure 1: Comparison of mean systolic blood pressure in the study groups before and at different time periods after intubation

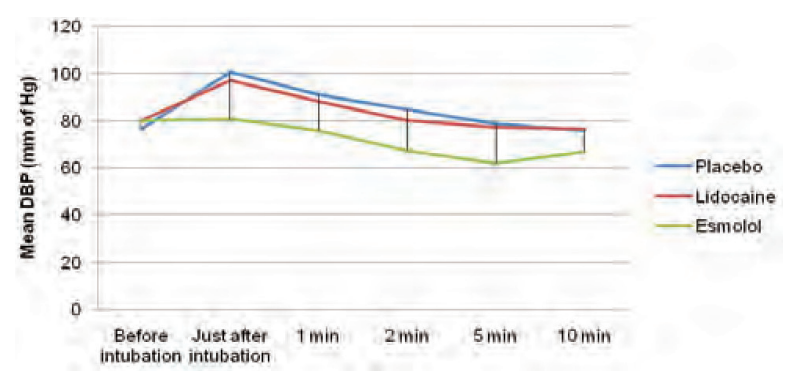

Figure 2: Comparison of mean diastolic blood pressure in the study groups before and at different time periods after intubation

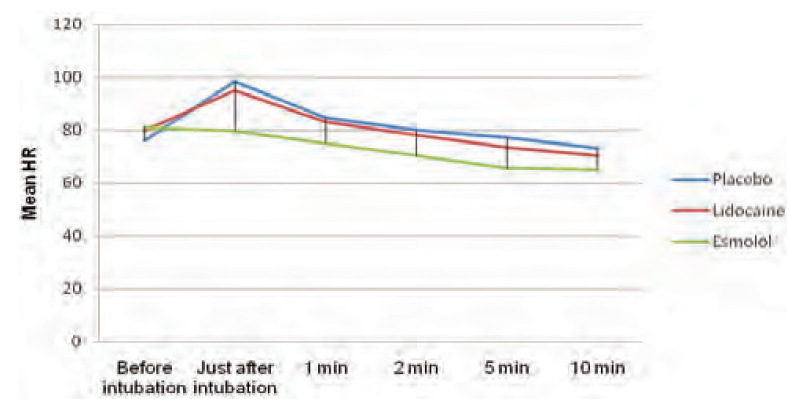

Figure 3: Comparison of mean heart rate in the study groups before and at different time periods after intubation

\section{Discussion}

Laryngoscopy and tracheal intubation is one of the main causes of hemodynamic instability. Transient hemodynamic changes may not be of any clinical importance in healthy patients but these changes are undesirable in patients with coronary artery disease, myocardial insufficiency, hypertension or cerebrovascular disease. ${ }^{20}$ Consequences of hemodynamic changes during laryngoscopy and intratracheal intubation can be prevented by using different stress blunting drugs. ${ }^{1}$

Heart rate and SBP can increase from $22-66 \%$ and $36-45 \%$ respectively depending on the method of induction if no specific measures are applied to prevent hemodynamic response. ${ }^{13,15,21}$ In our study just after intubation HR, SBP and DBP were increased by $29.74 \%, 22.75 \%$ and $28.71 \%$ respectively in placebo group whereas in lidocaine group it was increased by $19.11 \%, 17.96 \%$ and $21.16 \%$ respectively. On the other hand, in esmolol group it was decreased below the baseline values throughout the whole study period. Regarding SBP, in both placebo and lidocaine group, it was stabilized only at 5 minutes after intubation, but DBP and HR were stabilized in lidocaine group after 2 minutes and in placebo group after 10 minutes. Patients with ischemic heart disease, intra cranial lesions and potential penetrating eye injuries are of greater risk for hemodynamic instability due to laryngoscopy and endotracheal intubation when specific care is not taken. ${ }^{22}$ Our study showed that esmolol was found to be more effective than lidocaine in various forms.

Lidocaine is effective in preventing the pressure response to tracheal intubation but not to increase in HR. ${ }^{1}$ This study reveals that esmolol $1.4 \mathrm{mg} / \mathrm{kg} \mathrm{IV}$ is superior to lidocaine $1.5 \mathrm{mg} / \mathrm{Kg}$ IV for attenuation of hemodynamic response to laryngoscopy and endotracheal intubation.

Esmolol has been found to be superior to lidocaine for attenuation of hemodynamic response to laryngoscopy and intubation in a study from Texas, USA. ${ }^{2}$ According to this study, esmolol is superior to lidocaine for attenuation of hemodynamic response to laryngoscopy and intubation. There were no significant differences between placebo group, esmolol group and lidocaine group in age, sex and ASA grading. Before intubation, the mean SBP, mean DBP and mean HR were not statistically significant with p-value $>0.05$ in placebo group, esmolol group and lidocaine group. In a study of a single bolus dose of esmolol in the prevention of intubation-induced tachycardia and hypertension in an ambulatory surgery unit, an IV bolus of esmolol $1.4 \pm 0.3 \mathrm{mg} / \mathrm{kg}$ significantly blunted increases 
in HR, and MAP following intubation. ${ }^{19}$ Esmolol $1.4 \mathrm{mg} \pm 0.4 \mathrm{mg} / \mathrm{kg}$ IV has been shown to attenuate the acute hypertensive response to tracheal intubation. ${ }^{23}$

It has been demonstrated that lidocaine $1.5 \mathrm{mg} / \mathrm{kg}$ IV was ineffective in attenuating the acute hemodynamic response to laryngoscopy and intubation whereas another study showed that lidocaine $1.5 \mathrm{mg} / \mathrm{kg}$ IV administered 3 minutes before intubation was highly effective in blunting the hemodynamic response to intubation. ${ }^{13,15}$ This study demonstrated that mean HR, mean DBP and mean SBP were significantly reduced just after intubation, 1 minute, 2 minutes, 5 minutes and 10 minutes only in esmolol group with $\mathrm{p}$-value $<0.05$ which was significant but in lidocaine group these parameters were reduced only after 2 minutes after intubation with $\mathrm{p}$-value $>0.05$, which was statistically insignificant when compared to placebo group.

The effects of the esmolol, lidocaine and nitroglycerine were compared and demonstrated that esmolol $1.4 \mathrm{mg} / \mathrm{kg} \mathrm{IV}$ was more effective than either lidocaine or nitroglycerine in controlling the HR response to laryngoscopy and intubation $(\mathrm{P}<0.05)$ and also showed that lidocaine $1.5 \mathrm{mg}$ / $\mathrm{kg}$ IV and nitroglycerine $2 \mathrm{mcg} / \mathrm{kg}$ IV were ineffective in blunting the acute hemodynamic stress response following laryngoscopy and intubation. ${ }^{13}$

Our study validates the results of similar studies reported from the University of Texas (1995) and Bangladesh (2010).2,13

\section{Conclusion}

Esmolol $1.4 \mathrm{mg} / \mathrm{kg}$ IV is superior to lidocaine $1.5 \mathrm{mg} / \mathrm{kg} \mathrm{IV}$ in controlling the hemodynamic response to laryngoscopy and intra-tracheal intubation. Therefore, esmolol might be the drug of choice in maintaining hemodynamic stability during laryngoscopy and intubation in patients with ischemic heart disease, hypertension and cerebrovascular disorder. However, a highly controlled study on these patients is recommended to establish the superiority of esmolol rather than the mere basis from outcomes of the studies on patients with ASA I and II physical status.

\section{References}

1. Bruder N, Ortega D, Granthil C. Consequences and prevention methods of hemodynamic changes during laryngoscopy and intratracheal intubation. Ann Fr Anesth Reanim. 1992;11:57-71.

2. Begum M, Akter P, Hossain MM, Alim SMA, Khatun UHS, Islam SMK, et al. A comparative study between efficacy of esmolol and lignocaine for attenuating haemodynamics response due to laryngoscopy and endotracheal intubation. Faridpur Med Coll J. 2010;5(1):25-28.

3. Shepard LC, Gelman S, Reeves JG. Humoral response of hypertensive patients to laryngoscopy. Anesth Analg. 1981;60:276-7.

4. Reid LC, Brace DE. Irritation of the respiratory tract and its reflex effect upon heart. Surg Gynecol Obstet. 1940;70:157-62.

5. ColemanAJ, Jordan C. Cardiovascular response to anesthesia. Influence of beta-adrenoceptor blockade with metoprolol. Anaesthesia. 1980;35(10):972-8.

6. Ebert TJ, Bernstein JS, Stowe DF, Roerig D, Kampine JP. Attenuation of hemodynamic responses to rapid sequence induction and intubation in healthy patients with a single bolus of esmolol. J Clin Anesth. 1990;2(4):243-52.

7. Rathore A, Gupta HK, Tanwar GL. Attenuation of the pressure response to laryngoscopy and endotracheal intubation with different doses of esmolol. Indian $\mathrm{J}$ Anaesth. 2002;46:449-52.

8. Stoelting RK. Attenuation of blood pressure response to laryngoscopy and tracheal intubation with sodium nitroprusside. Anesth Analg. 1979:58(2):116-9.

9. Mikawa $\mathrm{K}$, Nishina $\mathrm{K}$, Maekawa $\mathrm{M}$, Obara $\mathrm{H}$. Comparision of nicardipine, diltiazem and verapamil for controlling the cardiovascular responses to tracheal intubation. Br J Anaesth. 1996;76(2):221-6.

10. Nishikawa T, Namiki A. Attenuation of the pressor response to laryngoscopy and tracheal intubation with intravenous verapamil. Acta Anaesthesiol Scand. 1989;33(3):232-5.

11. Ghignone M, Calvillo O, Quintin L. Anesthesia and hypertension: the effect of clonidine on perioperative hemodynamics and isoflurane requirements. Anesthesiology. 1987;67:3-10.

12. Marino PL. The ICU Book. $3^{\text {rd }}$ ed. Lippincott Williams \& Wilkins; 2007.

13. Singh H, Vichitvejpaisal P, Gaines GY, White PF. Comparative effects of lidocaine, esmolol, and nitroglycerin in modifying the hemodynamic response 
to laryngoscopy and intubation. J Clin Anesth. 1995;7(1):5-8.

14. Feng CK, Chan KH, Liu KN, Or CH, Lee TY. A comparison of lidocaine, fentanyl, and esmolol for attenuation of cardiovascular response to laryngoscopy and tracheal intubation. Acta Anaesthesiol Sin. 1996;34(2):61-7.

15. Helfman SM, Gold MI, DeLisser EA, Herrington CA. Which drug prevents tachycardia and hypertension associated with tracheal intubation: lidocaine, fentanyl, or esmolol? Anesth Analg. 1991;72(4):482-6.

16. Liu J, Latson TW, Wu G, White PF. Effects of IV and/ or aerosolized lidocaine on the hemodynamic and EEG responses to laryngoscopy and tracheal intubation. Anesthesiology. 1993;79:A157.

17. Miller CD, Warren SJ. IV lignocaine fails to attenuate the cardiovascular response to laryngoscopy and tracheal intubation. Br J Anaesth. 1990;65(2):216-9.

18. Wang YQ, Guo QL, Xie D. Effect of different doses of esmolol on cardiovascular responses to tracheal extubation. Hunan Yi Ke Da Xue Xue Bao. 2003;28(3):259-62.

19. Parnass SM, Rothenberg DM, Kerchberger JP,
Ivankovich AD. A single bolus dose of esmolol in the prevention of intubation-induced tachycardia and hypertension in an ambulatory surgery unit. J Clin Anesth. 1990;2(4):232-7.

20. Fox EJ, Sklar GS, Hill CH, Villanueva R, King $\mathrm{BD}$. Complications related to the pressor response to endotracheal intubation. Anesthesiology. 1977;47(6):524-5.

21. Wilson IG, Meiklejohn BH, Smith G. Intravenous lignocaine and sympathoadrenal responses to laryngoscopy and intubation. The effect of varying time of injection. Anaesthesia. 199;46(3):177-80.

22. Khan N, Aslam M, Naz N, Khan MR. Comparative effects of lidocaine and esmolol in modifying the hemodynamic response to laryngoscopy and intubation. Pak J Med Health Sci. 2013;7(2):301-6.

23. Miller DR, Martineau RJ, Wynands JE, Hill J. Bolus administration of esmolol for controlling the haemodynamic response to tracheal intubation: the Canadian Multicentre Trial. Can J Anaesth. $199^{`} ; 38(7): 849-58$

24. Tam S, Chung F, Campbell M. Intravenous lidocaine: optimal time of injection before tracheal intubation. Anesth Analg. 1987;66(10):1036-8. 